\title{
Leakage Current Analysis and FFT Calculation on Polluted Polymer Insulator
}

\author{
I. A. Joneidi, A. A. Shayegani, H. Mohseni, S. Mohseni, and M. Jebeli-Javan
}

\begin{abstract}
In case of wet pollution, pollution layer create an appropriate path for leakage current and increasing of this pollution leads to more values of this leakage current. Therefore for better recognition of insulator changing process from normal state to fault outbreak, studying of leakage current and artificial aging models is necessary. In this paper, the experimental test results on polymer insulator with voltage of $20 \mathrm{KV}$ have been shown. Artificial aging on insulators has been done using solid layer methods according to IEC60507 standard. Leakage current waveforms during the experimental studies were measured. Normally fast Fourier transform (FFT) method used to find the harmonic spectrum in the leakage currents. Three states of analysis are considered. In the first stage, it is done with nominal voltage and without arc. In the second state, it is done in presence of dry band arcing and corona discharge and in the last case, continues arc is investigated and in each stage harmonic analysis is performed. It is observed that in last stage the $3^{\text {rd }}$ harmonic components increase rather than two previous stages.
\end{abstract}

Index Terms-Artificial aging, leakage current, polymer insulator, solid layer pollution.

\section{INTRODUCTION}

Polymeric insulators were considered as replacement for porcelain and glass for special applications such as areas with high incidences of vandalism, urban locations with limitations on right of way and areas of severe contamination problems due to their superior properties such as light weight, superiority in mechanical strength and high hydrophobicity[1].

Where silicon rubber is used as an outdoor insulator, various environmental factors such as ultraviolet light, rain and air pollutant deteriorate the material properties. Then, tracking and erosion are caused by electrical factors such as arc and corona partial discharges, when the power system is in operation tracking and erosion of polymer sheds, chalking and crazing of sheds which lead to increased contamination, arcing and flashover, bonding failures and electrical breakdowns along the rod-shed interface and corona splitting of sheds which lead to electrical breakdown [2].

It is well known that aging, which leads either to tracking or erosion or to flashover under contaminated conditions at normal operating voltage, is still the main cause of failures for non-ceramic insulators [3]. Exposure to dirty environment makes easily insulators polluted. After the polluted layer being wetted, the insulation capacity of the contamination insulator will be decrease, and flashover is

Manuscript received October 9, 2012; revised November 15, 2012.

The authors are with High Voltage Research Center, School of Electrical and Computer Engineering, University of Tehran, Tehran, Iran. (E-mail: i.ahmadi@ut.ac.ir; shayegani@ut.ac.ir;_mohseni@ut.ac.ir; sal44@yahoo.com; morvarid_javan@yahoo.com). often invited which seriously impacts the reliability of power supply. Pollution existence and humidity increase the leakage current and surface arc. Subsequently it leads to insulator electrical flashover and loss of transmission lines [4].

The electrical characteristics of the material for a long-term have not been explained sufficiently. Therefore, the foundations of estimation index and diagnostic methods are strongly required. Until now, there has been considerable research effort in the development of diagnostic methods. The diagnostic factors are surface conductivity, hydrophobicity, equivalent salt deposit density ESDD, flashover voltage FOV and leakage current.

The leakage current provides information on the amount of contamination on a polluted insulator. The relationship between the leakage current and the discharge phenomena have investigated on the polymer material under wet condition. In general, during aging test, two kinds of discharges are observed that can evaluate the insulation performance. One of them is corona partial discharge that occurs between water droplets. The other is dry band arc discharge that occurs between dry bands on the surface of the polymeric material that may cause tracking and erosion phenomena, its cumulative charge is much larger than that of a corona discharge[5].

Therefore study of the pollution effects on the leakage current and avoiding of its occurrence will get much special importance and in this paper, both of leakage current and FFT analysis of polymeric insulator has investigated on artificial pollution.

\section{EXPERIMENTAL TEST}

\section{A. Experimental Setup}

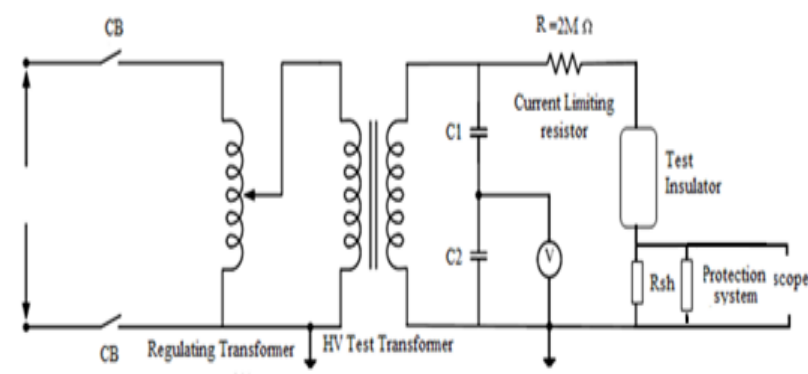

Fig. 1. Schematic of experimental setup

In order to execute the tests on contaminated insulators and measure leakage current and save the data, the laboratory setup was prepared as shown in Figure 1. This setup consists of $100 \mathrm{kV}, \mathrm{HV}$ transformer that used for energizing the insulators to the required voltage stress, data acquisition system provided the LC (Leakage current) related 
information, i.e. the time variation of LC, such as maximum, average waveforms. data acquisition consist of digital oscilloscope to save data, protecting circuit was used to isolate measuring instruments from high voltage and it consist of back connected Zener diodes (15 V) for overvoltage protection, Shunt resistor was used for measuring leakage current.

\section{B. Insulators Contamination}

Because of the initial hydrophobic nature of polymeric insulators it is rather difficult to apply artificial contaminants and to ensure that they adhere to the surface for the duration of the test. A method of application of artificial contamination on SiR (silicon Rubber) which was reported to provide a uniform contamination layer was discussed in [6]. Kaolin Powder is deposited after spraying the surface with a fine mist of water droplets and allowing it to dry. The insulator is immersed in the slurry of contaminants and dried. Kaolin composition consists of $40 \mathrm{~g}$ kaolin, $1000 \mathrm{~g}$ tap water and $10 \mathrm{~g} \mathrm{NaCL}$. When the Volume conductivity of tap water is higher than $0.05 \mathrm{~S} / \mathrm{m}$, the use of distillery water is recommended [6].

\section{Test Insulators}

Two Silicone Rubber (SiR) insulators of rating $20 \mathrm{kV}$ (L-L) were used for laboratory artificial aging study. Fig.2 illustrates the Photographs of actual insulators as well as test arrangements. Table 1 shows the characteristics of tested insulators. After measuring leakage current, ESDD was measured according to IEC60507 to determine the amount of insulators' surface contamination level.

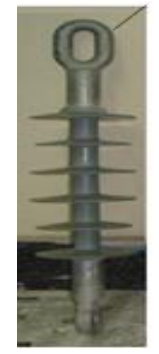

Fig. 2. Photograph of tested insulator

TABLE I: CHARACTERISTICS OF TESTED INSULATOR

\begin{tabular}{|c|c|c|}
\hline Specification & unit & $\mathrm{SiR}$ \\
\hline Insulator number & - & 1 \\
\hline Voltage class & $\mathrm{KV}$ & 20 \\
\hline Leakage distance & $\mathrm{mm}$ & 770 \\
\hline Shed diameter & $\mathrm{mm}$ & 100 \\
\hline height & $\mathrm{mm}$ & 235 \\
\hline $\begin{array}{c}\text { Mechanical tension } \\
\text { Strength }\end{array}$ & $\mathrm{KN}$ & 70 \\
\hline
\end{tabular}

\section{LEAKAGE CURRENT UNDER CLEAN SURFACE}

Initially a clean $20 \mathrm{KV}$ silicon rubber polymer insulator was tested with an applied voltage of $11.5 \mathrm{kVrms}$. No visual discharges were observed under this test condition. Fig. 3(a) shows the typical waveform of LC obtained at this test condition. It is noticed that even at high relative humidity negligible amount of LC only flows on the surface of the insulator due to clean surface condition. Fig.3 (b) shows the Frequency spectrum plot of the leakage current during clean surface condition. It is observed that the LC signal under clean surface condition contains the higher order harmonic components like $4^{\text {th }}, 5^{\text {th }}$, and $7^{\text {th }}$. Also, it is noticed it was observed that in clean condition, the $5^{\text {th }}$ harmonic component was always greater than the $3^{\text {rd }}$ harmonic. That is, the insulator was in its normal condition. In the polluted dry condition the harmonic content does not change, its look like a clean condition.

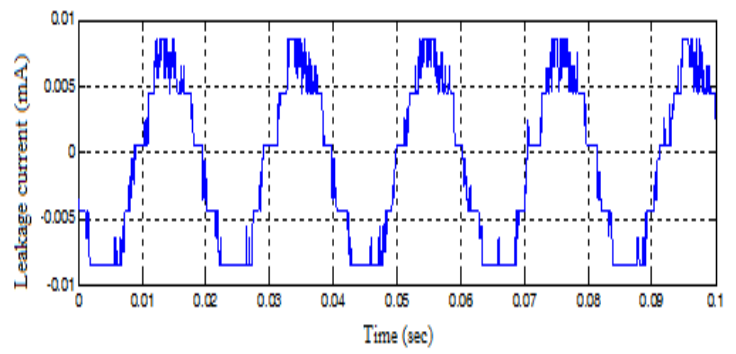

Fig. 3.a. Leakage current of $20 \mathrm{KV}$ clean insulator

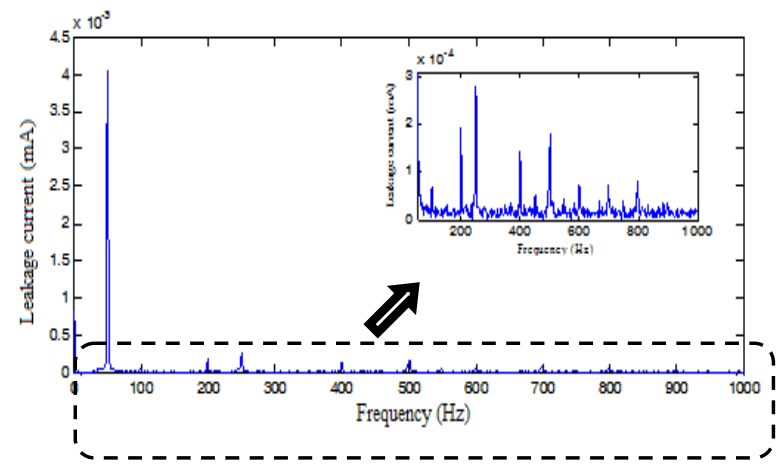

Fig. 3.b. Frequency spectrum of leakage current on $20 \mathrm{KV}$ clean insulator

\section{LEAKAGE CURRENT UNDER POLLUTION CONDITION}

Sometimes transmission and distribution lines passes near the coastal, desert and industrial areas. Therefore, insulators are exposed to the outdoor environment. In this environment, different types of contaminants like $\mathrm{NaCI}, \mathrm{CuSo} 4$ salts are coming from the different sources and deposited on the insulator surface. Salt contamination makes a drastic reduction in the breakdown insulation level of the affected insulators, which will lead to flashover.

Artificial ageing tests should simulate actual field conditions as much as possible and test results should be validated by the performances in actual fields. They want to evaluate degree of ageing deterioration of a polymer insulator by means of the magnitude of leakage current and/or its cumulative charge flowing on that specimen polymer insulator. It is pointed out; however, that conductive current flowing only in contaminated and wetted layer on the surface of a polymer insulator without any discharge would not deteriorate the surface so much compared with the case of corona discharge or dry band arc currents. The typical surface leakage current pattern has been recorded on the following three levels:

\section{A. Conductive Current}

For completely wet surfaces, which were obtained in the successive contamination tests, LC also appeared to be 
sinusoidal but resistive and at higher level (Fig.4 (a)). The cases in which the hydrophobic properties were either partially lost or a weak dry band activity started, the patterns could be resistive and nonlinear. It is observed that the LC signal (Fig.4 (b)) shows the Frequency spectrum plot of the leakage current during pollution surface condition. It is observed that the LC signal under pollution condition contains the $3^{\text {th }}$ harmonic components greater than $5^{\text {th }}$ and other harmonic component. All of the result was shown in table 2 .

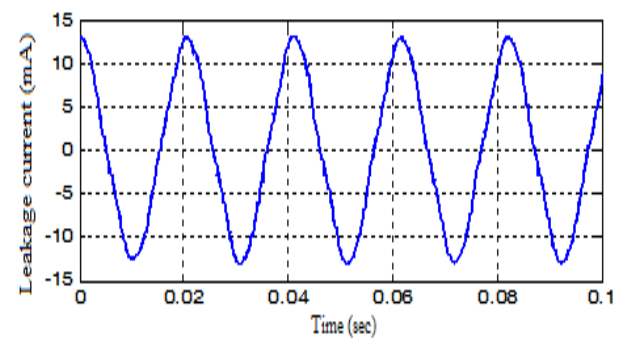

Fig. 4.a. Leakage current of $20 \mathrm{KV}$ polluted insulator

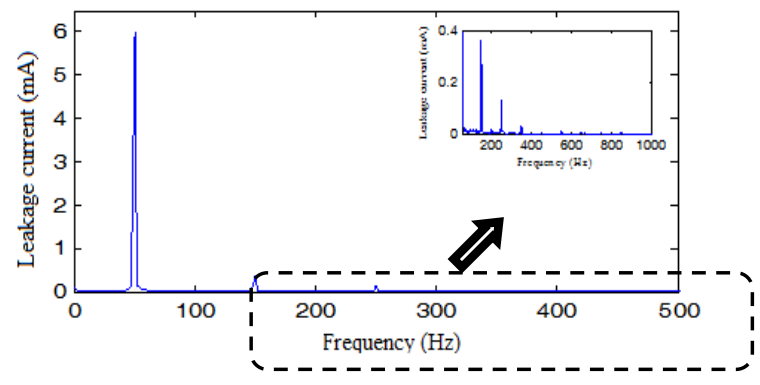

Fig. 4.b. Frequency spectrum of leakage current

TABLE II: RESULT OF LEAKAGE CURRENT AND HARMONIC ANALYSIS ON POLLUTED INSULATOR

\begin{tabular}{|r|c|}
\hline $\begin{array}{r}\text { Maximum of leakage } \\
\text { current }(\mathrm{mA})\end{array}$ & 13.08 \\
\hline $1^{\text {st }}$ harmonic $(\mathrm{mA})$ & 6.017 \\
\hline $3^{\text {rd }}$ harmonic $(\mathrm{mA})$ & 0.3684 \\
\hline $5^{\text {th }}$ harmonic $(\mathrm{mA})$ & 0.1314 \\
\hline $7^{\text {th }}$ harmonic $(\mathrm{mA})$ & 0.03365 \\
\hline $9^{\text {th }}$ harmonic $(\mathrm{mA})$ & 0.01131 \\
\hline $11^{\text {th }}$ harmonic $(\mathrm{mA})$ & 0.01028 \\
\hline $13^{\text {th }}$ harmonic $(\mathrm{mA})$ & 0.00485 \\
\hline
\end{tabular}

\section{B. Dry Band Arcing and Corona Arcing}

We have investigated the relationship between the leakage current and the discharge phenomenon on the polymer material under moist condition. In general, two kinds of discharges are observed during test which can evaluate the insulation performance. One of them is corona partial discharge that occurs between water droplets, in which $\mathrm{Si}-\mathrm{C}$ bonding of silicon rubber is broken down by photon energy because the photon energy due to the corona discharge is larger than the bonding energy of $\mathrm{Si}-\mathrm{C}$. Therefore, the corona discharge activity on the hydrophobic surface can be used to define the insulation surface condition. The other is dry band arc discharge that occurs between dry bands on the surface of the polymeric material. Thus, the dry band arc discharge and the corona discharge influence the insulator performance and therefore it is necessary to investigate their characteristics in aging test [7].
The nonlinear behavior, as the one in Fig.5(a) occurred during and prior to the visible discharge activity and, therefore, the discharge currents can be considered as a spike appearing on the crest of a nonlinear LC waveform. Fig.5 (b) shows the Frequency spectrum plot of the leakage current during pollution surface condition. It is observed that the LC signal under pollution condition contains the $3^{\text {rd }}$ harmonic components great higher than $5^{\text {th }}$ and other harmonic component. All of the result was shown in table 3 .

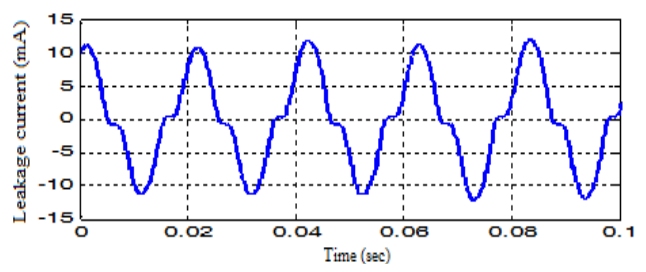

Fig. 5.a. Leakage current of 20KV contain dry band arcing

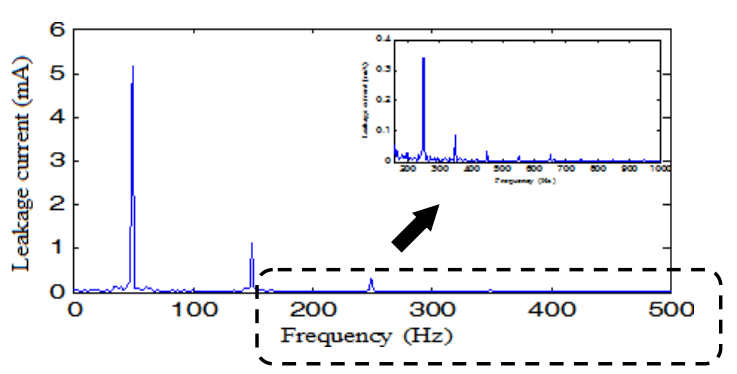

Fig. 5.b. Frequency spectrum of leakage current on $20 \mathrm{KV}$ polluted insulator contain dry band arcing

TABLE III: RESULT OF LEAKAGE CURRENT AND HARMONIC ANALYSIS ON POLLUTED INSULATOR CONTAIN DRY BAND ARCING

\begin{tabular}{|r|r|}
\hline $\begin{array}{r}\text { Maximum of leakage } \\
\text { current(mA) }\end{array}$ & 5.167 \\
\hline $1^{\text {st }}$ harmonic(mA) & 1.131 \\
\hline $3^{\text {rd }}$ harmonic(mA) & 0.3404 \\
\hline $5^{\text {th }}$ harmonic $(\mathrm{mA})$ & 0.086 \\
\hline $7^{\text {th }}$ harmonic $(\mathrm{mA})$ & 0.03335 \\
\hline $9^{\text {th }}$ harmonic $(\mathrm{mA})$ & 0.02021 \\
\hline $11^{\text {th }}$ harmonic $(\mathrm{mA})$ & 0.02398 \\
\hline $13^{\text {th }}$ harmonic $(\mathrm{mA})$ & 5.167 \\
\hline
\end{tabular}

\section{Fully Arcs with Dry Band Arcing}

The partial discharges will elongate along the surface and lead to fully arch. This condition is the previous stage of the insulator flashover. Fig.6 (a) shows these phenomena. It is observed that the $3^{\text {rd }}$ harmonic components increase rather than two previous stage. Fig 6(b) shows the result. All of the result about leakage current and harmonics of leakage current was shown in table 3.

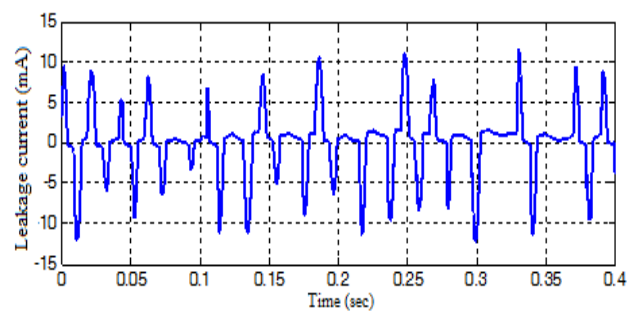

Fig. 6.a. Leakage current of $20 \mathrm{KV}$ polluted insulator contain fully arcing with dry band arcing 


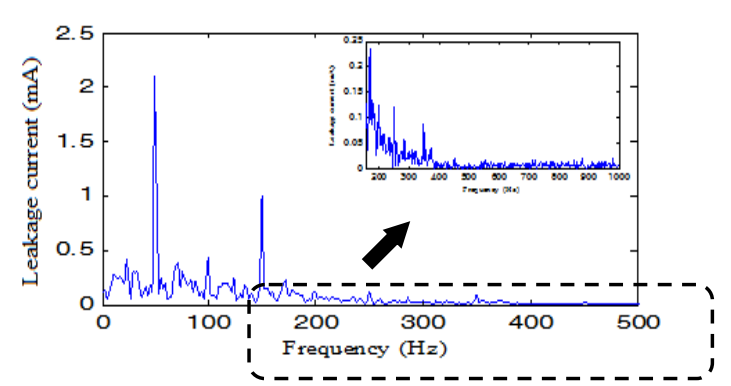

Fig. 6.b. Frequency spectrum of leakage current on $20 \mathrm{KV}$ polluted insulator contain fully arcs with dry band arcing

TABLE IV: RESULT OF LEAKAGE CURRENT AND HARMONIC ANALYSIS ON POLLUTED INSULATOR CONTAIN FULLY ARCING WITH DRY BAND ARCING

\begin{tabular}{|r|l|}
\hline $\begin{array}{r}\text { Maximum of leakage } \\
\text { current }(\mathrm{mA})\end{array}$ & 2.1 \\
\hline $1^{\text {st }}$ harmonic $(\mathrm{mA})$ & 1.011 \\
\hline $3^{\text {rd }}$ harmonic $(\mathrm{mA})$ & 0.1227 \\
\hline $5^{\text {th }}$ harmonic $(\mathrm{mA})$ & 0.09058 \\
\hline $7^{\text {th }}$ harmonic $(\mathrm{mA})$ & 0.01695 \\
\hline $9^{\text {th }}$ harmonic $(\mathrm{mA})$ & 0.0132 \\
\hline $11^{\text {th }}$ harmonic $(\mathrm{mA})$ & 0.0121 \\
\hline $13^{\text {th }}$ harmonic $(\mathrm{mA})$ & 2.1 \\
\hline
\end{tabular}

\section{CONCLUSION}

Experimental results on polymer insulator to understand the pollution severity by harmonic content of leakage current signal has been presented in this paper. Experimental test results on two insulators with profile and voltage of have been done. Third harmonic components of leakage current waveform are closely related to the pollution on the insulator. Under clean conditions, no flashover occurred during the tests, When 3rd harmonic is lower than 5st harmonic, the insulators have no or very light contamination. Therefore, harmonic analysis of leakage current will be an efficient approach to determine the pollution severity of outdoor polymer insulators. Dry band discharges are observed during test which can evaluate the insulation performance, when discharge start, 3rd harmonic component increase obviously rather than foundation harmonic. Discharge activity, observed as spikes on the crest of the waveform due to formation of dry bands.

\section{REFERENCES}

[1] M. Group, A Comparison between Silicone Rubber Composite Insulators and RTV coated Glass Insulators, USA, 2003.

[2] J. M. Seifert and W. Hubl, "Hydrophobicity effect of silicone housed composite insulators and its transfer to pollution layers-Design and environmental parameters influencing the hydrophobic surface behavior," Iraklion symposium, Kreta, Greece, 26\&27 th April, 2001.

[3] H. Deng, E. A. Cherney, and R. Hackam, "Effects of particles size of ATH fillers on the performance of RTV rubber coatings," in IEEE Electrical Insulation and Dielectric Phenomena Conference, pp. 598-604,1993.

[4] Y. Liu and J. K. Wang, "Analysis of large area pollution flashover occurred in Shannxi power network on Dec.18, 2000 and Preventative measures for similar accidents," Power System Technology, vol. 26, pp. 82-85, June 2002.

[5] M. Otsubo, T. Hashiguchi, C. Honda O. Takenouchi, T. Sakoda, and Y. Hashimoto, "Evaluation of insulation performance of polymeric surface using a novel separation technique of leakage current," IEEE Transactions on Dielectrics and Electrical Insulation, vol. 10, no. 6, December 2003.
[6] IEC Standard 60815, "Guide for Selection of Insulators in Respect of Polluted Condition," 1986

[7] F. F. Bologna, J. P. Reynders, and A. C. Britten, "Corona discharge activity on a string of glass cap-and-pin insulators under conditions of light wetting, light non-uniform contamination," IEEE Bologna PowerTech Conference, Bologna, Italy June 23-26, 2003.

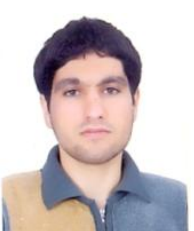

Iman Ahmadi Joneidi was born in Ghaemshahr, Iran, in 1984. He received his B.S degree in Noshirvani University of Technology, Babol, Iran in 2007 and M.Sc. degrees in electrical engineering from the University of Tehran, Tehran, Iran, in 2010. Since 2007 to now, he has been with the High Voltage laboratory. His areas of interest are Electrical Insulation and Dielectrics Partial Discharge Diagnostics. He has been a researcher of the Iran Power Generation and Transmission Company (TAVANIR). Now he is as a researcher at high voltage laboratory of university of Tehran.

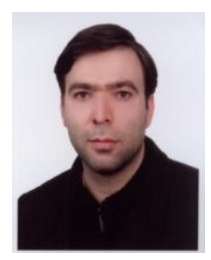

Amir Abbas Shayegani Akmal received the B.Sc. degree from the Sharif University of Technology, Tehran, Iran in 1996 and M.Sc. and Ph.D. from the University of Tehran in 1998 and 2005, respectively all in electrical engineering. He worked at the High Voltage Laboratory of the Sharif University of Technology and University of Tehran, as assistant. He worked toward his Ph.D. through the cooperation between the University of Tehran and University of Hannover (ScheringInstitute). Currently, he is an Assistant Professor at Electrical and Computer Engineering Department of University of Tehran. He works in high voltage laboratory and his principal research interest is in high voltage insulation systems, testing, and diagnostics.

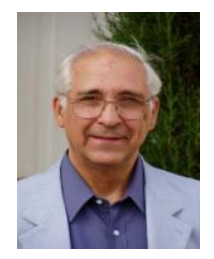

Hossein Mohseni received the Dipl. Ing and Dr. Techn from Technical University Graz, Austria in 1971 and 1975, respectively. From 1971 to 1976 he was with ELIN UNION AG Austria, working as testing and research engineer in the High Voltage Laboratory and the Transformer R and D Department. In 1976 he joined the Faculty of Engineering, University of Tehran, Department of Electrical Engineering where is currently a Professor and teaches high voltage engineering, high voltage insulation technology, and transients in power System and Apparatus. During 1981/82 he was the chairman of Department of electrical engineering at the University of Tehran. Since 1980 he has been a technical consultant of the Iran Power Generation and Transmission Company (TAVANIR). Also since 1998 he is the dean of the High Voltage and Pulsed Power research center, at the University of Tehran.

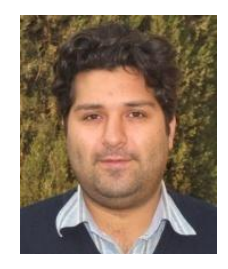

Salman Mohseni was born in Tehran, Iran, in 1984 Since 2002 to now, he has been a researcher and test assistant at High Voltage and Lighting laboratories of the University of Tehran. His areas of interest are high voltage testing techniques and lighting measurements. He received Second Position Award of Kharazmi Student Festival in Science and Technology 2003.

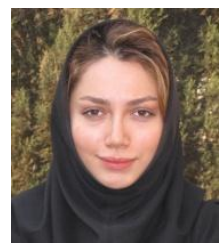

Morvarid Jebeli Javan was born in Tehran, Iran, in 1986. She received her B.Sc. in power engineering from Power and Water University of Technology at 2008. Since 2007to now, she has been a researcher and test assistant at High Voltage and Lighting laboratories of the University of Tehran. Her areas of interest are high voltage testing techniques and lighting measurements. 